\title{
EDITORIAL
}

\section{0th volume anniversary of Polymer Journal}

\author{
Polymer Journal (2018) 50, 1; doi:10.1038/pj.2017.73
}

\section{$\mathrm{I}$}

Tn 2018, Polymer Journal will publish the 50th volume. The first issue Iof Polymer Journal launched in 1970. Since then, Polymer Journal has published about 6800 manuscripts. These papers have greatly contributed to the development of the field of polymer science and its related fields. We publish this special issue (Vol. 50, No. 1) to celebrate this occasion. From North America, Europe, China and Japan, seven review and five focus review papers written by world-renowned polymer scientists have been collected. This special issue covers a wide range of polymer science topics from syntheses, structures, functions (photo-, electro-, bio-functions) and interfaces of macromolecules and emerging related materials. I would like to thank all authors of this issue, Professors Akimitsu Narita, Klaus Muellen, Xi Zhang, Christopher K. Ober, Deqing Zhang, Hiroyuki Nishide, Mitsuo Sawamoto, Atsushi Harada, Kazunori Kataoka, Atsushi Takahara, Yoshiki Chujo, Mitsuru Ueda and Toshikazu Takata, for writing these excellent papers. I also contributed our review paper. The keywords of these papers reflect topical issues in the field of polymer science. I am sure that these papers will be widely read and will have a great impact on polymer science.

In the history of Polymer Journal, the most-cited paper published throughout the issues since 1970 is Professor Donald Tomalia's paper that reports dendrimers for the first time. ${ }^{1}$ This work was published as a paper based on his invited talk at the 1st SPSJ International Polymer Conference (IPC 84 Kyoto), which was held in Kyoto, during 20-24 August 1984. Personally, I attended Prof Tomalia's invited lecture when I was a graduate student. This paper has been cited more than 2500 times (September 2017) according to the Web of Science, Clarivate Analitics. The second most-cited paper is the contribution of Professor Ishihara and Professor Nakabayashi, which was one of the important reports in the field of biomaterials. ${ }^{2}$ The third most-cited paper was written by Professor Tadokoro. The paper discloses the crystalline structures of poly(vinylidene fluoride). ${ }^{3}$ Professor Shirakawa, who is a Nobel laureate, published a couple of papers on polyacetylenes in Polymer Journal. Two of his papers are the fourth and fifth most-cited papers. ${ }^{4,5}$ I am sure Polymer Journal will continue to publish cutting-edge and important papers in the field of polymer science and related fields.

Finally, I would like to thank all readers, authors, referees, editors, editorial assistants and publishers for their contribution to Polymer Journal. We are looking forward to receiving your manuscript for future issues.

\section{CONFLICT OF INTEREST}

The author declares no conflict of interest.

Takashi Kato

Editor-in-Chief

The University of Tokyo, Tokyo, Japan

E-mail: hpj@spsj.or.jp

1 Tomalia, D. A., Baker, H., Dewald, J., Hall, M., Kallos, G., Martin, S., Roeck, J., Ryder, J. \& Smith, P. A new class of polymers: starburst-dendritic macromolecules. Polym. J. 17, 117-132 (1985).

2 Ishihara, K., Ueda, T. \& Nakabayashi, N. Preparation of phospholipid polymers and their properties as polymer hydrogel membranes. Polym. J. 22, 355-360 (1990).

3 Hasegawa, R., Takahashi, Y., Chatani, Y. \& Tadokoro, H. Crystal structures of three crystalline forms of poly(vinylidene fluoride). Polym. J. 3, 600-610 (1972).

4 Shirakawa, H. \& Ikeda, S. Infrared spectra of poly(acetylene). Polym. J. 2 231-244 (1971).

5 Shirakawa, H., Ito, T. \& Ikeda, S. Raman scattering and electronic spectra of poly (acetylene). Polym. J. 4, 460-462 (1973). 